\title{
Immunohistological identification of interleukin-1 activated chondrocytes
}

\author{
John T Dingle, M Elisabeth Davies, Brenda Y Mativi, Helen F Middleton
}

\begin{abstract}
Interleukin-1 activated chondrocytes have been identified in pig articular cartilage by immunolocalisation using a polyclonal antiserum recognising cytokine induced surface epitopes. Although chondrocytes with membrane staining were noted in all zones of the cartilage, only a proportion of the cells were positive within the range of antiserum dilution used (1:100-1:2000). Maximum staining was found after fours days' treatment of cultured cartilage with pig IL-1 $\alpha$, though weak staining was just detectable after treatment for one day at high antiserum concentration. Immunoreactivity was also shown in cartilage which had been cultured with human recombinant IL-1 $\alpha$.
\end{abstract}

Since the first observation that cytokine messengers derived from synovial tissue were able to degrade cartilage matrix and prevent its repair $^{1}$ intense interest has centred on the nature of the cytokine/cartilage interactions. The principal cytokines controlling articular cartilage matrix turnover are now known to be interleukin-1 $\alpha$ (IL-1 $\alpha$ ) and IL-1 $\beta$ and possibly tumour necrosis factor, ${ }^{2}$ though the second messenger involved has not yet been elucidated. Reports $^{4-6}$ suggest that monolayer cultured chondrocytes stimulated with IL-1 release a variety of enzymes, including latent metalloproteinases, which, upon in situ activation, would be capable of degrading both collagen and proteoglycan. ${ }^{78}$ Such studies indicate that chondrocyte activation by IL-1 may play a part in the control of the dynamic equilibrium between synthesis and degradation in cartilage matrix. Therefore, the immunological detection of such enzymes would provide a useful indicator of cytokine induced chondrocyte activation and a direct means of attributing local sites of matrix degradation to enzyme secretion by individual cells. Despite numerous attempts, however, it has been impossible to immunolocalise these enzymes in IL-1 treated adult cartilage (Hembry $\mathbf{R} \boldsymbol{M}$, personal communication and unpublished $\mathrm{PhD}$ thesis), in contrast with observations on chondrocytes in monolayer cultures or postfetal cartilage in culture. Hence the enzymes cannot be used as a marker for chondrocyte activation in cytokine mediated cartilage damage in adult tissue.

At the present time there is no means of directly identifying activated chondrocytes within the cartilage, or of determining whether particular indigenous chondrocytes are more susceptible to the cytokine, or indeed whether there are differences in cytokine activation of chondrocytes in different regions of the cartilage. The immunocytochemical detection of the surface epitopes described in this study is believed to be the first identification of individual IL-1 activated chondrocytes within articular cartilage.

\section{Materials and methods}

TREATMENT OF CARTILAGE IN CULTURE WITH IL-1 $\alpha$

Cartilage was obtained by dissection from the chondylar ridge of the metacarpophalangeal joints of 6-9 month old pigs. Paired explants of tissue were taken from the joint for comparative histological and biochemical studies and were cultured in $0.5 \mathrm{ml}$ of medium (Dulbecco's minimum essential medium; Gibco) containing $120 \mu \mathrm{g} / \mathrm{ml}$ benzylpenicillin and $200 \mu \mathrm{g} / \mathrm{ml}$ streptomycin supplemented with $5 \%$ heat inactivated fetal calf serum. The cultures were set up in 25-well plastic dishes (Sterilin) and maintained at $37^{\circ} \mathrm{C}$ in a $5 \% \mathrm{CO}_{2}$ environment. Pig IL-1 $\alpha$, purified as described by Saklatvala et $a l,{ }^{2}$ or human recombinant IL $1-\alpha$ was added to the culture for a period of one, two, or four days at a final concentration of $2 \mathrm{ng} / \mathrm{ml}$.

Controls were paired explants of untreated cartilage, which were maintained in culture under similar conditions for the same time periods.

Sterile conditions were maintained throughout.

\section{PREPARATION OF CHONDROCYTES}

Chondrocytes were released from the cartilage under sterile conditions by overnight enzymic digestion in medium containing $10 \mathrm{mg}$ of collagenase/g of tissue at $37^{\circ} \mathrm{C}$. The cells were rigorously washed by centrifugation, resuspended in medium containing $5 \%$ heat inactivated normal rabbit serum, and counted. A total of $2 \times 10^{7}$ cells were plated into $90 \mathrm{~mm}$ diameter plastic cell-culture Petri dishes (Corning) in $10-15 \mathrm{ml}$ of medium. The cultures were maintained at $37^{\circ} \mathrm{C}$ in a $5 \% \mathrm{CO}_{2}$ environment, and the medium was changed after two days. The cells were grown to confluence and were then either maintained as untreated controls or treated with $5 \mathrm{ng} / \mathrm{ml}$ pig IL-1 $\alpha$ for 16 hours, after which time they were harvested, washed three times in phosphate buffered saline (PBS) by centrifugation and resuspended in PBS to give a cell density of about $10^{7} / \mathrm{ml}$. The IL-1 treated chondrocytes were used for immunisation and the untreated, normal chondrocytes were used for adsorption of the antiserum. 
PRODUCTION OF ANTICHONDROCYTE SERUM

A blood sample was obtained before immunisation, and about $10^{7} \mathrm{IL}-1 \alpha$ treated chondrocytes were injected in $2 \mathrm{ml}$ of PBS into a New Zealand White rabbit at six subcutaneous sites. Three repeat injections were given at monthly intervals and test blood samples were obtained at seven to eight days after injection. Serum was stored at $-20^{\circ} \mathrm{C}$ until used.

\section{PRODUCTION OF ANTISERUM TO IL-1 INDUCED EPITOPES}

The antiserum produced by injection of IL-1 treated chondrocytes as described above was rendered specific for IL-1 induced epitopes by 'exhaustive' sequential adsorption with normal untreated pig chondrocytes, chondrocytes fixed with $4 \%$ paraformaldehyde, and washed pig red blood cells. Antiserum (1 ml) was diluted to $5 \mathrm{ml}$ in PBS and mixed with the cell pellet containing about $10^{8}$ cells to give an even suspension. After incubation for one to two hours at $37^{\circ} \mathrm{C}$ on a roller rack the cells were removed by centrifugation and discarded; the serum was stored at $-20^{\circ} \mathrm{C}$.

\section{IMMUNOHISTOCHEMICAL METHODS}

Frozen sections $8 \mu \mathrm{m}$ thick were cut, fixed in 4\% paraformaldehyde for 30 minutes, washed twice in PBS, and stored overnight at $4^{\circ} \mathrm{C}$ in a moist atmosphere.

Sections were treated for one hour at room temperature with either PBS, preimmune serum, or rabbit anti-IL-1 stimulated chondrocyte serum at various dilutions ranging from $1: 100$ to $1: 5000$. All dilutions were made in PBS. After thorough washing in PBS $(3 \times 15$ minutes on a gentle shaker) the sections were incubated with the second antibody, fluorescein isothiocyanate conjugated pig antirabbit immunoglobulin (Dakopatts), diluted 1:200 in PBS for one hour at room temperature. After washing as above the sections were mounted in Citifluor (glycerol/PBS) and viewed on a Zeiss IM 35 microscope fitted with epifluorescence and photographed on Kodak Ektachrome film ASA 400, uprated during processing to 1600 ASA. In some experiments chondrocytes were visualised by counterstaining with $0.01 \%$ methyl green for two minutes before mounting. Paired serial sections were stained with toluidine blue for light microscopical examination.

\section{MEASUREMENT OF CARTILAGE PROTEOGLYCAN DEGRADATION}

Degradation of cartilage proteoglycan was determined by measurement of the glycosaminoglycan released into the medium compared with that in papain digested cartilage. ${ }^{9}$ The glycosaminoglycans were assayed using the metachromatic dye, dimethyl methylene blue (Serva Feinbiochemica), in an automated modification of the method described by Farndale $e t$ $a l .{ }^{10}$ Whale chondroitin sulphate was used as a standard.

\section{Results}

IMMUNOFLUORESCENT STAINING OF PIG

\section{ARTICULAR CARTILAGE}

Serial sections of either IL-1 treated or untreated articular cartilage explants wère examined for fluorescent staining after incubation with antiserum raised by injecting IL-1 stimulated pig chondrocytes into a rabbit, as described in 'Materials and methods'.

Sections which had been incubated with the unadsorbed antiserum at dilutions down to 1:5000 showed intense membrane staining in most cells in all regions of both untreated and IL-1 treated cartilage. Diffuse staining of the matrix was also seen spreading across the articular surface into the mid-zone. Maximum fluorescence was observed in sections from cartilage which had been exposed to IL-1 for four days. After only one day of IL-1 treatment higher concentrations of antiserum (1:2000) showed weak matrix staining and membrane staining in a few cells in the articular surface.

\section{LOCALISATION OF IL-1 INDUCED EPITOPES}

Exhaustive adsorption of the antiserum with normal chondrocytes completely eliminated immunoreactivity against untreated cartilage as shown in fig $D$, in which the unreactive cells can be visualised by their counterstained nuclei. Conversely, chondrocytes from IL-1 treated cartilage reacted with the adsorbed antiserum as shown by their marked membrane fluorescence (figs $A$ and B), which could be detected at antibody dilutions down to $1: 2000$. Fluorescence intensity was maximal after IL-1 treatment of the cartilage for four days, though weak membrane staining was seen in a few cells after one day.

Immunoreactive chondrocytes were found in all regions of the cartilage from the articular surface, through the mid-zone to the hypertrophic zone. It is abundantly clear, however, that not all cells were positive (fig $A$ ), and a more detailed time-course study is currently in progress to assess the proportion of unreactive cells within the different zones. A similar distribution of membrane stained chondrocytes was seen in cartilage which had been treated with human recombinant IL-1 $\alpha$ for four days, using the adsorbed antiserum at dilutions of $1: 100$ or $1: 250$ (fig B).

The specificity of the antiserum was confirmed by the absence of membrane fluorescence when PBS or preimmune serum (fig C) was used as control.

\section{DEGRADATION OF MATRIX PROTEOGLYCAN}

Histological assessment of proteoglycan release from the matrix in response to pig IL-1 $\alpha$ was by toluidine blue staining of serial sections of paired explants of cartilage. Progressive loss of metachromasia spread from superficial to deeper zones during IL-1 treatment over four days. Biochemical estimation of glycosaminoglycans showed that after IL-1 treatment for one day 25.4 (SD 13.7)\% proteoglycan was released into the medium, whereas by four days most of the matrix proteoglycan had been depleted $(92 \cdot 0(5 \cdot 3) \%$ released) (table). 

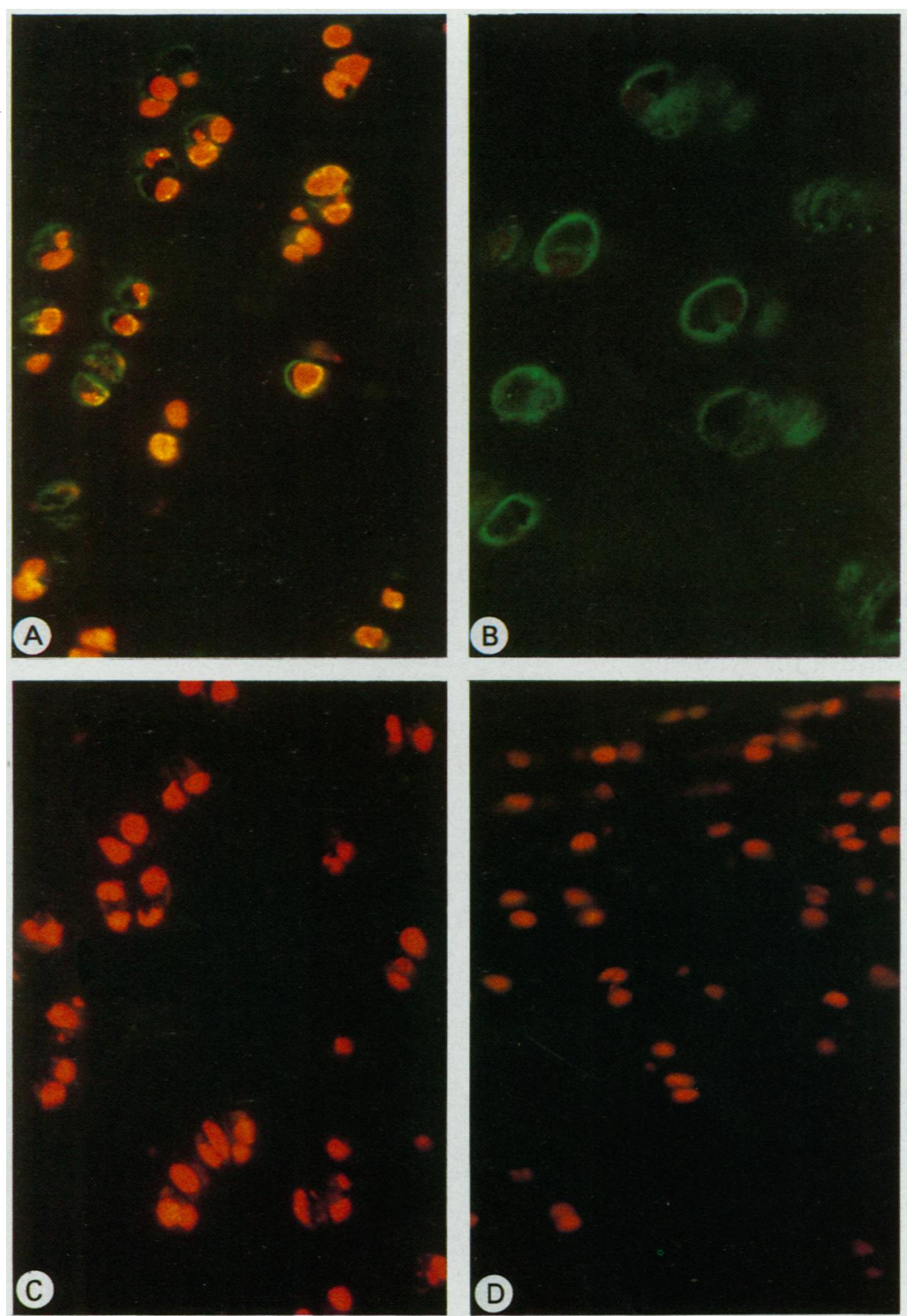

Localisation of surface epitopes on interleukin-1 (IL-1) activated chondrocytes in frozen sections ( 8 \%m thick) of pig articular cartilage explants which had been cultured in the presence or absence of IL-1 for four days. (A) Mid-zone chondrocytes after culture with pig IL-1 $\alpha$

$(2 \mathrm{ng} / \mathrm{ml})$. Sections were incubated with adsorbed antiserum at dilution of 1:250.

(B) Mid-zone chondrocytes a fter culture with human recombinant IL-1 $\alpha(2 \mathrm{ng} / \mathrm{ml})$. Sections were incubated with adsorbed antiserum at dilution of 1:250. (C) Mid-zone chondrocytes after culture with pig IL-1 $\alpha(2 \mathrm{ng} / \mathrm{ml})$. Sections were incubated with preimmune serum at dilution of $1: 250$. (D) Control, untreated articular surface/mid-zone chondracytes. Sections were treated with adsorbed antiserum at dilution of 1:250.

Glycosaminoglycan release from interleukin-1 (IL-1) treated pig articular cartilage (mean (SD) of three determinations)

\begin{tabular}{lll}
\hline $\begin{array}{l}\text { IL-1 treatment } \\
\text { (days) }\end{array}$ & \multicolumn{2}{c}{ Percentage proteoglycan } \\
\cline { 2 - 3 } & $\begin{array}{l}\text { Released into } \\
\text { medium }\end{array}$ & $\begin{array}{l}\text { Remaining in } \\
\text { cartilage }\end{array}$ \\
\hline 0 & $8 \cdot 7(2 \cdot 9)$ & $91 \cdot 3(4 \cdot 7)$ \\
1 & $25 \cdot 4(13 \cdot 7)$ & $74 \cdot 6(5 \cdot 1)$ \\
2 & $49 \cdot 1(7 \cdot 1)$ & $50 \cdot 9(9 \cdot 6)$ \\
4 & $92 \cdot 0(5 \cdot 3)$ & $8 \cdot 0(3 \cdot 4)$ \\
\hline
\end{tabular}

\section{Discussion}

In the work reported in this paper we set out to determine whether it was possible to identify indigenous cartilage chondrocytes that had been activated by IL-1. Although the two principal actions on cartilage-namely, the increased catabolism of the extracellular matrix molecules and the inhibition of proteoglycan synthesis, have been well reported in many animal and human cartilages, there has been no report of any method which identifies whether these effects are due to all the cells in the cartilage or to cells at specific sites or, indeed, to individual cells in a particular area.

We report here the recognition of individual IL-1 activated chondrocytes in situ using an antiserum which had been raised against IL-1 stimulated pig chondrocytes and subsequently exhaustively adsorbed with normal, untreated pig chondrocytes. The specific immunoreactivity of the adsorbed antiserum was confirmed by recognition of IL-1 induced surface epitopes on indigenous chondrocytes in IL-1 treated explants, whereas chondrocytes in cartilage which had not been exposed to the cytokine showed no evidence of activation.

The observation of IL-1 induced new surface epitopes is not new. Indeed, Bevilaqua et al have already described the endothelial leucocyte adhesion molecule (ELAM 1), which is induced by a variety of cytokines, including IL-1, ${ }^{11}$ and there have been many reports of cytokine induced changes in expression of surface molecules in a wide variety of tissues. ${ }^{12-16}$ As far as we know there have been no previous reports describing new surface epitopes induced on chondrocytes in intact articular cartilage by IL1 activation. The Ia antigen has been observed on the surface of chondrocytes in diseased tissue but is reported to be induced by interferon gamma. ${ }^{17} 18$ The membrane expression of the IL- 1 induced molecules further excludes the metalloproteinases which are exclusively cytoplasmic, being localised around the Golgi apparatus in secretory granules. ${ }^{46}$

Clearly, the expression and characterisation of such surface epitopes will provide a useful tool in determining the role of cell activation by cytokines both in immune recognition and in inflammation. Consequently, experiments are currently in progress to characterise biochemically our adsorbed antiserum in an attempt to define the IL-1 induced epitope(s), and it will be of interest to compare our findings with those of Mollenhauer $e t a l^{19}$ who have used the rather different approach of investigating autoantibody production to examine chondrocyte surface components.

A further interesting finding in our study is that although we are able to detect activated chondrocytes in all zones of the IL-1 treated cartilage (and it should be remembered that in these in vitro organ culture experiments we are using an excess of IL-1), only a proportion of the cells seem to be 'switched on' at any one time, regardless of the duration of the IL-1 treatment or the dilution of the antiserum. This observation may suggest that individual cells differ in their susceptibility to cytokine activation at a particular time, though Van den Berg et al recently reported no evidence of enhanced susceptibility of particular chondrocytes to IL1 , as determined by suppression of proteoglycan synthesis in intact articular cartilage. ${ }^{20}$ Alternatively, the expression on the membrane may be transient, such that at any given time only a proportion of the cells would appear activated. At present we are unable to distinguish between these two possibilities. 
This study aimed at providing a means of identifying individual cytokine activated chondrocytes for the purpose of investigating their possible role in the pathogenesis of reversible cartilage degradation. Our results clearly show immunorecognition of IL-1 induced cell activation; however, from these preliminary observations we are unable to correlate directly chondrocyte activation with matrix degradation. The heterogeneity of activated chondrocytes may suggest that we are looking at an early event preceding the progressive proteoglycan depletion. A study of the kinetics of chondrocyte activation in the various zones within the cartilage might well be of importance in the understanding of the processes entailed in the local turnover of cartilage matrix. It still remains to be shown whether cellular interactions between the synovium and cartilage, and in particular at the edge of invading pannus, are directly involved in the release of the cytokines and the activation of the adjacent chondrocytes. The use of immunorecognition of activated cells offers the first definitive means of testing this hypothesis. The correlation of local zones of erosion with the recognition of surface epitopes is feasible both in in vitro cocultures of synovium and cartilage and in experimental synovitis in animals. It should also prove possible with the development of antibodies to human chondrocyte epitopes to determine whether these cells have been switched on in an analogous manner using surgically removed tissue.

We thank Dawn Ward and Margaret Flack for excellent technical assistance. The human recombinant interleukin-l $\alpha$ was a gift from Ciba-Geigy.

1 Dingle J T. Recent studies on the control of joint damage: the contribution of the Strangeways Research Laboratory. Ann Rheum Dis 1979; 38: 210-14.

2 Saklatvala J, Pilsworth L M C, Sarsfield S J, Gavrilovic J, Heath J K. Pig catabolin is a form of interleukin 1. Biochem f 1984; 224: 461-6.

3 Lane Smith R, Allison A C, Schurman D J. Induction of articular cartilage degradation by recombinant interleukin $1 \alpha$ and $1 \beta$. Connect Tissue Res 1989; 18: 307-16.

4 Murphy G, Hembry R M, Reynolds J J. Characterization of a specific antiserum to rabbit stromelysin and demonstration of the synthesis of collagenase and stromelysin by stimulated rabbit articular chondrocytes. Coll Relat Res 1986; 6: 351-64.

5 Murphy G, Hembry R M, McGarrity A M, Reynolds J J, Henderson B. Gelatinase (type IV collagenase) immunolocalization in cells and tissues: use of an antiserum to rabbit bone gelatinase that identifies high and low $M_{\mathrm{r}}$ forms. $\mathcal{F}$ Cell Sci 1989; 92: 487-95.

6 Hembry R M, Murphy G, Cawston T E, Dingle J T, Reynolds J J. Characterization of a specific antiserum for mammalian collagenase from several species: immunolocalization of collagenase in rabbit chondrocytes and uterus. I Cell Sci 1986; 81: 105-23.

7 Deshmukh-Phadke K, Lawrence M, Nanda S. Synthesis of collagenase and neutral proteases by articular chondrocytes: collagenase and neutral proteases by articular chondrocytes: stimulation by a macrophage derived
Biophys Res Commun 1978; 85: 490-6.

8 Campbell J K, Golds E E, Mort J S, Roughley P J. Human articular cartilage secretes characteristic metal-dependent proteinases upon stimulation with mononuclear cell factor. Fheumatol 1986; 13: 20-7.

9 Saklatvala J. Characterization of catabolin, the major product of pig synovial tissue that induces resorption of cartilage proteoglycan in vitro. Biochem $\mathcal{F}$ 1981; 199: 705-14.

10 Farndale R W, Sayers C A, Barrett A J. A direct spectrophotometric microassay for sulfated glycosaminoglycans in

11 Bevilaqua M P, Pober J S, Mendrick D L, Cotran R S, Gimbrone $M$ A. Identification of an inducible endothelial leukocyte adhesion molecule. Proc Natl Acad Sci USA 1987; 84: 9238-42.

12 Dustin M L, Rothlein R, Bhan A K, Dinarello C A, Springer $T$ A. Induction by ILI and interferon gamma, tissue distribution, biochemistry, and function of a natural adherence molecule (ICAM-1). F Immunol 1986; 137: 245-54.

13 Bevilaqua M P, Pober J S, Majeau G R, Fiers W, Cotran R S, Gimbrone M A. Recombinant tumor necrosis factor induces procoagulant activity in cultured human endothelium: characterization and comparison with the actions of in
leukin 1. Proc Natl Acad Sci USA 1986; 83: 4533-7.

14 Simmons D, Makgoba $M$ W, Seed B. ICAM, an adhesion ligand of LFA-1 is homologous to the neural cell adhesion ligand of LFA-1 is homologous to the neural
molecule NCAM. Nature 1988; 331: 624-7.

15 Cavender D E, Edelbaum D K. Inhibition by IL-1 of endothelial cell activation induced by tumor necrosis factor or lymphotoxin. F Immunol 1988; 141: 3111-6.

16 Hale L P, Martin M E, McCollum D E, et al. Immunohistologic analysis of the distribution of cell adhesion molecules within the inflammatory synovial micromolecules within the inflammatory syno

17 Burmester G R, Menche D, Merryman P, Klein M, Winchester $R$. Application of monoclonal antibodies to the characterization of cells eluted from human articular chartilage. Arthritis Rheum 1983; 26: 1187-95.

18 Goldring M B, Sandell L J, Stephenson M L, Krane S M. Immune interferon suppresses levels of procollagen mRNA Immune interferon suppresses levels of procollagen mRNA and type II collagen synthesis in cultured human articular and costal chondrocytes. F Biol Chem 1986; 261: 9049-56.

19 Mollenhauer J, Von der Mark K, Burmester G, Glückert K, Lütjen-Drecoll E, Brune E. Serum antibodies against chondrocyte cell surface proteins in osteoarthritis and rheumatoid arthritis. F Rheumatol 1988; 15: 1811-7.

20 Van den Berg W B, Van de Loo F A J, Zwarts W A, Otterness I G. Effect of murine recombinant interleukin on intact homologous articular cartilage: a quantitative and autoradiographic study. Ann Rheum Dis 1988; 47: 855-63. 